See discussions, stats, and author profiles for this publication at: https://www.researchgate.net/publication/272739975

\title{
A Review of Corrosion in Agricultural Industries
}

Article · January 2015

DOI: 10.9734/PSIJ/2015/14847

CITATIONS

5

2 authors:

Makanjuola Oki

Landmark University

29 PUBLICATIONS 119 CITATIONS

SEE PROFILE

Some of the authors of this publication are also working on these related projects:

Project chromate conversion coatings View project

Project In-Country Utilization of Nigeria Crude Oil View project
READS

2,714

Paul A L Anawe

Covenant University Ota Ogun State, Nigeria

54 PUBLICATIONS 106 CITATIONS

SEE PROFILE 


\title{
A Review of Corrosion in Agricultural Industries
}

\author{
Makanjuola $\mathrm{Oki}^{\mathbf{1}^{*}}$ and Paul. A. L. Anawe ${ }^{2}$ \\ ${ }^{1}$ Department of Mechanical Engineering Landmark University P.M.B. 1001, Omu-Aran, Kwara State, \\ 251101, Nigeria. \\ ${ }^{2}$ Department of Petroleum Engineering, Covenant University, Idiroko Road, Ota, Ogun State, \\ Nigeria.
}

\section{Authors' contributions}

This work was carried out in collaboration between both authors. Author MO designed the study and wrote the first draft of the manuscript. Author PA managed the literature and contributed to the second and third drafts. Both authors read and approved the final manuscript.

Article Information

DOI: $10.9734 / P S I J / 2015 / 14847$ Editor(s):

(1) Xi Wu, Mechanical Engineering Department, California Polytechnic State University, San Luis Obispo, USA

(2) Abbas Mohammed, Blekinge Institute of Technology, Sweden.

Reviewers:

(1) Mohamed Ahmed Sayed Ahmed Afifi, Mechanical Engineering, MTI University, Egypt.

(2) Anonymous, India.

(3) Ugi, Benedict Ushaka, Department of Pure and Applied Chemistry, University of Calabar, Nigeria. Complete Peer review History: http://www.sciencedomain.org/review-history.php?iid=835\&id=33\&aid=7590

Review Article

ABSTRACT

Corrosion is ubiquitous and ravages all sectors of world economies of which agricultural industries are not immune. Techniques abound to stop corrosion theoretically and practically however, human errors and over enthusiastic application of available methods of protection have reduced their applications to practical reduction of corrosion rates of materials of construction. This review highlights chemicals and agricultural wastes which enhance corrosion rates of materials of construction and practical ways of reducing their effects.

Keywords: Corrosion inhibitors; fertilizers; aluminium; stainless steel; mild steel; pesticides; silage.

\section{INTRODUCTION}

One of the largest sectors of world economy is the agriculture and horticulture industry. They are quite capital intensive. Investments per acre are varied, depending on the type of activities involved. It is not easy to define exactly where corrosion can be most damaging in agriculture due to the diverse nature of structures, machinery and fittings employed for farming purposes. This is further compounded by environmental factors such as rural, urban and 
coastal indices. Also of concern are climatic, type of farming activities as well as the seasonal use of specific equipment and machinery and the various storage methods employed [1].

The degree of corrosion of a metal is largely dependent on the environment in which it is put to use. The atmospheric behaviour of metals in wet conditions and in soil differs, therefore protective treatments must be chosen in accordance with environments. While it is appropriate to use temporary protection such as grease impregnated with or without corrosion inhibitors, it is more important to select materials which can withstand the type(s) of corrosion envisaged in a particular environment. It will be inappropriate to use copper and its alloys in environments laden with ammonia or its derivatives so also stainless steel equipment in chloride environments. They will suffer from stress corrosion cracking (SCC) [2].

In designing buildings and structures, the corrosiveness of the atmosphere must be assessed. Expectedly, coastal areas are considered to have higher corrosion tendencies than those inland. This is also applicable to tall structures and those sites exposed on hillsides. Likewise it is believed that corrosion is more prevalent downwind of industrial areas which are always laden with nitrous and sulphur oxide gases which promote acid rains [3]. Studies [4] have shown that corrosion damage is not always uniform in nature and it is usually localised to small areas resulting in premature failure or damage. Such failures are usually associated with microbiologically influenced corrosion (MIC). Prevention could be achieved through good design and the adoption of best practice and good house keeping in equipment use.

\section{CORROSION BY AGRICULTURAL CHEMICALS AND THEIR CONTROL}

Fertilisers, grains and silage preservatives, pest chemicals, disease and weed control, and proprietary acid solutions for cleaning dairy equipment are common examples of chemicals largely used in farming.

Farm wastes and slurries are known to be considerably corrosive. Also, chemicals most significantly damaging to farming structures and machinery, are acid preservatives, additives, some fertilisers and manures/slurries. As regards acid cleaning chemicals, these can be used along with eco-friendly and bio-degradable corrosion inhibitors in order to reduce their damaging effects [5-10].

There are different types of fertilisers with varied levels of corrosiveness. The determinants of corrosiveness include the decomposition or reactions to produce aggressive substances such as ammonia or hydrogen sulphide; especially where chloride ions are present like potassium or ammonium chloride or where acidic conditions are prevalent. For instance, ammonium nitrates or di-hydrogen ammonium phosphate are known to engender material degradation through hydrolysis to acids resulting in a fall in $\mathrm{pH}$. The ratio of essential plant nutrients could affect the degree of corrosiveness of compound liquid fertilisers. It is believed that the effect is most evident with fertiliser solutions containing about $15 \%$ nitrogen; more so when half the free nitrogen is derived from urea and half from ammonium nitrate.

A study [11] shows that for fertilisers containing nitrogenous solution of ammonium nitrate and urea reacts only slowly with steels and the reaction becomes more rapid at welds and bolt holes. Welded steels suffer from depletion of alloying components at the heat affected zones (HAZ) and bolt holes constitute crevices where corrosion will be more intensified. In the same study, it was shown that phosphate solutions containing ammonium phosphate are less reactive towards steel, forming a phosphate passive layer which protects the underlying substrate.

When fertilisers are dry, there is zero or very minimal corrosion. However, because of their hygroscopic nature they can easily attract moisture thereby becoming corrosive. Fertilisers become hygroscopic at a particular relative humidity and for ammonium nitrate, the value is $60 \%$ [12] which makes the compound to be highly corrosive since it turns into liquid at a relatively low relative humidity. Some other phosphates only absorb moisture when their $\mathrm{RH}$ values are above $90 \%$. Initial contact with moisture causes fertilisers to cake causing a marked increase in its abrasive properties. To encourage increased resistance to corrosion it is advised that steel be galvanised. Evidence abounds in tests where it was shown that fertiliser chemicals are more aggressive towards mild steels than towards galvanised steels [13]. Corrosion rate values quoted for $63 \%$ saturated ammonium nitrate solution are about $250 \mathrm{~mm}$ for galvanised steel as against $1,250 \mathrm{~mm}$ for mild 
steel in the first year of exposure. Carbon steel provides a cheap option for the containment of fertilisers, as long as adequate surface cleaning, preparation and coating are done. Type 304 stainless steel was observed to be of most benefit for liquid fertiliser service from tests done over a three-year period. Penetration values quoted for tanks exposed for about 2.5 years to commercial liquid fertilisers are in the region of $0.253,282$ and $132 \mu \mathrm{m}$ for Type 304 stainless steel, carbon steel and 5052 aluminium respectively.

A better control of the onset and progression of corrosion by fertiliser solutions can be achieved through better design of equipment and enhanced maintenance and cleaning. Also, the use of inhibitors with fertilisers during storage, transportation and application also help reduce corrosion. Sulphur compounds, like thiourea, ammonium thiocyanate and 2-mercapto benzothiazole, are known to be suitable inhibitors for mild steel exposed to a mixture of ammonium nitrate-ammonia-water system in the absence of urea. Relative successes have been reported with the use of polyphosphates such as sodium polyphosphate, dibasic ammonium phosphate, for aqueous ammonium nitrate/ammonia/urea. However, free ammonia can reduce inhibitive effects of orthophosphate by reacting with it to form a complex salt. [7]. In addition, there is a huge abundance of renewable inhibitors of plant origin which are readily available for use in agricultural settings.

Organic acids produced during the process of ensilage can cause corrosion damage in tower silos. It has been observed [12] that whole crop maize silage ferments easily giving acidic by products with $\mathrm{pH}$ values as low as 3.6 which are very corrosive towards the internals of silos. In the same vein, lactic acid which is a stronger acid in combination with oxygen, give secondary fermentation resulting in silage with predominantly butyric acid, which gives a relatively higher $\mathrm{pH}$ value. However, corrosion rates inside silos are usually higher than those on the external walls because temperatures inside silos are usually higher than those in the outside environment. This is understandable since every $10^{\circ} \mathrm{C}$ rise in temperature doubles the rates of reaction including corrosion reactions.

Formic acid has been used extensively over the years to prevent the growth of moulds and bacteria on stored grains. Other acids in the aliphatic carboxylic group, including propionic acid, have also been employed. Generally, the contact time for acids on machinery for example on augers and balers, is quite low, hence corrosion rates are usually very low on mild steel. Propionic acids are highly corrosive, however, damage could be minimised if the right precautions such as the complete removal of the acid-treated grain from the silo after use, washing with water, and avoidance of contact of treated grains with unprotected machinery.

During storage, acid-treated grains are less prone to cause corrosion, the major precaution needed being to minimise the risk of concentration in local areas such as crevices, or where stagnant pools of liquid can easily collect [14]. These are detrimental to metals as a result of differential aeration corrosion in such crevices.

The problem of paint-stripping properties associated with organic acid additives can be contained by the modification of their compositions. For instance, complex formation through the addition of a cation to the organic acid will render it ineffective as a paint stripper $[15]$ Others $[15,16]$ have observed that silos built of aluminium has provided over 10 years of service life while the use of enamelled steel has been encouraged for its ease of maintenance and cleaning. Plastic coatings and enamelled surfaces are prone to cracking which will result into creation of crevices with the attendant creation of crevice corrosion situations. On the other hand, galvanised steel usually deteriorate easily when in contact with silage juices and slurries which are most often highly acidic in nature. Aluminium is the most preferred metal for the construction of storage vessels, followed by galvanised steel and then mild steel [16].

Usually silage from the bottom of the silo has a consistency akin to chipboard therefore equipments used for conveying and unloading silage can be subjected to corrosive wear. Abrasion and acid attack are also particularly destructive to concrete as acids are known to react with lime which causes the concrete to become friable. Thus, this encourages the concrete to crack and eventually spall further exposing the internal structure to inclement weather. Plastics, chlorinated rubber and epoxy based coatings are resistant to acid attacks and will provide alternatives as floor coverings over concretes in agricultural environments. 


\subsection{Corrosion by Slurries/Manures and its Control}

Animal husbandry has developed astronomically with the advent of domestication of animals that were hitherto been hunted in the wild. Grasscutters, rabbits and with increasing demand for milk from cows, goats and related species has resulted in the growth in associated problems of handling manure and related waste materials. Consequently, equipment and associated handling devices have received attention from manufacturers to develop suitable materials which will cope with the high increase in waste generation. Slurries are mixtures of dung and urine which are normally composted with litter (probably a mix of straw or wood shavings) to form farm yard manure. The farm yard manure (FYM) ferments to release moisture, ammonia and carbon dioxide and in conjunction with naturally excreted chlorides from animals constitute the major corrosive components of slurries and farm yard manures. These are very corrosive to steel structures and ill-maintained, agricultural equipment and components. Here selection of materials and avoidance of crevice situations in the design stages come into play and will forestall insidious corrosion problems such as seizures of machinery etc. Results [13] have shown that galvanised steel is not significantly beneficial for some manure, especially those derived from poultry and cattle. However, manufacturers still favour the use of galvanised steel or concrete for livestock floors. In the case of piglets where copper compounds are incorporated in the feed, tests results show that galvanised metal thickness losses are close to $0.1 \mathrm{~mm} /$ year. This could be attributed to the effect of local deposit/galvanic corrosion. It has been observed that when there is a mixture of silage effluent and slurry a dangerous concentration of hydrogen sulphide gas can be formed which will encourage the formation of corrosive acids under deposits.

\subsection{Corrosion by Herbicides Pesticides and its Control}

The past decade has witnessed an enhanced growth in the development of chemicals for the use of crop protection. Simultaneously, there has been growth in corrosion by herbicides and pesticides. This is significantly noticeable under certain conditions, especially if harmful species concentrate in local areas. A common feature associated with incompatible metals is that copper-bearing fluids such as Bordeaux mixture an outcome of a mix of copper sulphate, water and lime is quite aggressive to aluminium or zinc as well as galvanised steel. This could be very harmful on new structures that have been freshly galvanised. Evidence from glasshouse structures shows that there is a significant increase in 'zinc drip' with the use of such copper-bearing fluids. It can be inferred that local deposits of copper will encourage the anodic dissolution of zinc in a suitable electrolyte hence the observed "zinc drip".

Serious waterline attack may occur on steel drums containing aqueous TCA, sodium trichloroacetate-weed-killer within a nine month period and heavier attacks have been observed on aluminium, galvanised steel, various brasses and copper while tinned steel and molybdenumcontaining stainless steel Type 316 were more resistant which essentially should be the preferred choice in the combat against corrosion. Common weed-killers like the nitro-phenolics have been implicated in the corrosion of spraying equipment made of steels, however, application of inhibited oils and greases have been found to forestall waterline attacks as a result of differential aeration corrosion. Although the use of dilute dichromate solution as inhibitor has been found effective for corrosion phenomena induced by the use of furfurals and related compounds, however, they have been implicated as carcinogens and are very harmful to the environment at large. Their usage in most industries has been limited by several protocols. Other insecticides and weed-killers that have corrosive actions on metals are chlordane, DDT in salt water as well as sodium arsenite. Stainless steel has the best corrosion resistance for use with herbicides and pesticides while aluminium and its alloys have given satisfactory performance. However, insecticides dissolved in fuel oils are found to be less aggressive as the solvents are of petroleum origin and could coat the surfaces of metals with a thin film in which case they perform the functions of inhibitors.

\subsection{Corrosion and its Control in Dairy Farming}

The use of stainless steels is wide spread in the dairy industry. Expectedly corrosion in this area is limited and relatively uncommon. However, specific problems may arise with cleaning and sterilisation of buildings and machinery, hence the need to protect steel structures from milk wastes. Lactic acid, for instance can easily 
corrode $1.25 \mathrm{~mm}$ of steel within a year. Agents containing chlorine, such as sodium hypochlorite disinfectant are potential corrosives to most metals associated with dairy industry equipment. The conjoint actions of stress and chlorides in environments in which stainless steel is put in service usually results in stress corrosion cracking more especially at temperatures in the region of about $70^{\circ} \mathrm{C}[2,17]$ and its use should be avoided as well in the presence of caustic solutions within this temperature regime. In addition, it is not advisable to use phosphoric acid in the removal of scale or milk stone in aluminium-based utensils and tinned surfaces should not be over-treated as this will cause tarnishing which may discolour the dairy products.

It is usually not advisable to use phosphoric acid in the removal of scale or milk stone in aluminium-based utensils and tinned surfaces should not be over-treated as this will cause tarnishing which may discolour the dairy products.

\section{CORROSION AND ITS CONTROL IN HIGH RISK PRONE AREAS}

In a recent survey of farmers and horticulturists it was found that corrosion damage to buildings and structures are comparable with damage to machinery and equipment. Evidence shows that metals like galvanised structures and sheeting, certain animal houses - notably piggeries - and units that handle fertilisers and slurries are highrisk areas where the influence of chemicals often in association with wear, can be significant.

\subsection{Structures and Buildings}

Corrosion occurs in galvanised structures when the protective zinc coating has been removed by acids or salty environments or any strong alkali. This is true, as galvanised sheets in rural environments could last more than 30 years, while in comparison the life span in a severely polluted, industrial area may be only five to ten years where acid rains are implicated as the agents of corrosion [18]. On the other hand, aggressive soils like peats or marshes containing sulphate and chloride or acid conditions engender higher corrosion rates in galvanised steel than may occur at ground level in some buildings. Also galvanised steel can neither withstand the severe condensation that is very common in farm buildings. It is often recommended that buildings sited in marine or other highly corrosive atmospheres should be painted. Consistently, calcium orthoplumbate alkyd primers with a matching alkyd top-coat are eminently easier to apply on galvanised steel where they have proved effective in reducing the ravaging effects of corrosion.

Animal houses are often highly laden with ammonia, thus it is usually recommended [15] that the roof of such should be made of double sheeting and at the same time good ventilation with adequate air spaces must be maintained. As regards materials selection, copper containing alloys should be avoided while corrosion resistant materials without protective coatings is basic designs aimed at reducing condensation effects beneath roof surfaces. An adequately ventilated piggery will remove gases, dust and odour, while air temperature and relative humidity will be controlled. In addition, excess heat and moisture will be controlled which will ensure appropriate oxygen levels. Naturally ventilated sheds should be separated by a distance of five times their height to maximise ventilation [19]. It is advised that adequate caution be taken for fixings and fasteners for buildings and equipment in order to avoid crevice corrosion where metals/alloys are in contact with timber especially if treated with preservatives containing copper, mercury or fluorides in damp conditions. Copper and mercury are cathodic to most metal thus when these are short circuited, the anodic, more active metal, aluminium or steel will corrode preferentially as a result of galvanic corrosion.

Options for the control of damage to metals in contact with timber include the isolation of the area with a suitable tape or bituminous layer, by dipping the metal in lanolin or tallow prior to fitting. Some timbers are naturally durable and are viable for diverse situations, including contact with the ground or other damp material. Jarrah and teak could last for over 50 years whilst other timbers such as chestnut, pine or cedar can have a life span of up to 20 years. Most timbers used for glasshouses in Europe are red wood, which are well preserved with preservative to underscore the risk of decay [20]. It is recommended that in cases where timbers are not treated with preservative they should be painted however, some paints such as emulsion are detrimental to plants' growth and should be avoided. In addition, vapours emitted during seasoning of wood are acidic and corrode nearby metals while actually not in contact in environments that are not well ventilated. This is 
common with woods like oak and sweet chestnut and should be avoided in combination with metallic surfaces of structures.

Active chemicals from poultry and pig farming can undermine the life span of farm fencing which usually have an average span of up to 14 years. Generally, galvanised steel has a longer life span than wood and mild steel for fences and gates as reported by Loto and co-workers [13]. It is also known that zinc used in cereal farms where there is a high usage of lime and chemical sprays are prone to heavier attacks. This may be due to the fact that zinc is anodic to mild steel and the zinc particles will only protect mild steels in its immediate vicinity while other larger unprotected areas will be left to the ravages of corrosion giving an uneven corrosion patterns.

Premature failure could occur in gutters due to poor maintenance, or poor locations during erection. To forestall such premature failures, sloping guttering design is favoured in order to minimise the formation of silt deposits and also to avoid the accumulation of pools of stagnant liquid which are most likely to be acidic solution from cleaning procedures.

\subsection{Equipment and Machinery}

Considerable care should be taken of machines that handle chemicals especially, artificial fertilisers and slurries as they are the most vulnerable to corrosion. To this end quality maintenance and care of machinery should be practiced after daily use and during out of season storage. Corrosion phenomenon rear its head in numerous ways which are not limited to seizure of equipment and moving parts as well as insidious unexpected leakages etc. Crevice corrosion in poorly drained areas, joints and the likes are common in agricultural establishments as a result of differential aeration. Corrosion in this case can be managed effectively through good house keeping which should be consolidated with the application of inhibited greases and oils for temporary protection in addition to the use of sealants. For agricultural equipment, while it may be quite economic to use highly corrosion resistant alloys and metals, however, some plastics are not too weak for some of the equipment. Nylon, polypropylene and acrylonitrile butadiene styrene (ABS) are found suitable for many agricultural environments [21].
From corrosion experiments, it has been observed that galvanised steels withstand the effects of agricultural wastes from livestock more than its mild steel counterpart $[13,22]$.

\section{CONCLUSION}

For machinery and equipment adequate cleaning and application of temporary corrosion protection with the use of inhibited oils and greases prior to storage in a well assessed facility is important to avoid damaging corrosion effects.

Location of agricultural sites should avoid heavily polluted industrial and salt laden coastal areas; different environments will induce different corrosion rates on materials of construction.

Both external and internal surfaces of buildings and structures should be well protected with paints and coatings suitable for the environment and stagnant conditions should be avoided. Also designs which encourage condensation must be avoided.

Agriculture or farming environment is hard on machinery and facilities thus their consistent protection is required from the daily exposure to water, fertilizers, cow manure and pesticides. Hence known and rigorously tested methods of corrosion prevention should be applied while in use and stored during seasons.

Good house keeping is of the essence in agricultural establishments for the reduction of damaging effects of corrosion.

\section{COMPETING INTERESTS}

Authors have declared that no competing interests exist.

\section{REFERENCES}

1. Augustin MA, Šcerbejova M. Anti corrosive efficiency of preservants for farming machinery. Res. Agr. Eng. 2003;49(1):2226.

2. Rogante $M$, Battistella $P$, Cesari $F$. Hydrogen interaction and stress corrosion cracking in hydrocarbon storage vessel and pipeline weldings. International Journal of Hydrogen Energy. 2006;31:597601.

3. Masayasu S, Kazuharu S, Akihiro K, Naoya I, Hachiro I. Zinc corrosion in 
simulated acid rain. Electrochimica Acta, 1999;44 (24):4307-4312.

4. Starosvetsky J, Starosvetsky D, Amon R. Identification of microbiologically influenced corrosion in industrial equipment failures. Engineering Failure analysis. 2007;14:1500-1511.

5. Oki M, Charles E, Alaka C, Oki TK. Corrosion inhibition of mild steel in $\mathrm{HCl}$ by tannins from Rhizophora Racemosa. Materials Science and Applications. 2011;2:592-595.

6. El-Etre AY. Inhibition of aluminum corrosion using Opuntia extract. Corrosion Science. 2003;45(11):2485-2495.

7. Oki M, Oki K, Otaigbe J, Otikor S. corrosion inhibition of aluminium in $\mathrm{HCl}$ by amine modified epoxy resin. Journal of Materials. 2013;5. Article ID 479728, 5 pages. Available: http://dx.doi.org/10. 1155/2013/479728,

8. Myrvold BO, Sandersen GK, Stylo T, Buvarp R, Seljebakken KB, Fredheim GE. Corrosion inhibitor containing diols and/or triols for metals in organic and inorganic acids. WO patent 2009035341 A1; 2009.

9. Myers CW, Hatch SR, Johnson DA, Bureman PE. Tungstate based corrosion inhibitors for inhibiting corrosion by a nitrogen fertilizer solution in contact with ferrous metal storage tanks, piping and equipment surfaces.US patent 289384; 2008.

10. Sangeetha M, Rajendran S, Sathiyabama J, Krishnaveni A, Shanthy P, Manimaran $\mathrm{N}$, Shyamaladevi B. Corrosion inhibition by an Aqueous Extract of Phyllanthus amarus. Portugaliae. Electrochimica Acta. 2011;29 (6):429-444.

DOI: 10.4152/pea.201106429.

11. Casales M, Salinas-Bravo VM, MartinezVillafane A, Rodriguez G. Effect of Heat Treatment on the Stress Corrosion Cracking of Alloy 690. Journal of Materials Science and Engineering A. 2002;332: 223-230.

12. Eker B, Yuksel E. Solutions to corrosion caused by agricultural chemicals. Trakia Journal of Sciences. 2005;3(7):1-6.
13. Loto CA, Popoola API. Environmental surface degradation of galvanised and mild steel in cattle and poultry wastes and urea solution. Int. Journal of the Physical sciences. 2011;6(3):3074-3051.

14. Banks HJ, Annis PC, Rigby GR. Controlled atmosphere storage of grain: the known and the future. In: Proceedings of the Fifth International Working Conference on Stored-Product Protection, Bordeaux, France, September 9-14. 1990;695-670,

15. National Physical Laboratory, Teddington, UK, Corrosion control of agricultural equipment and buildings. 2012;1-11.

16. Vreeland DC, Kalin SH. Corrosion of metals by liquid fertiliser solution. The Journal of Science and Engineering. 1956;12(11):53-59.

17. Rondelli G, Vicentini B, Sivieri E. Stress corrosion cracking of stainless steels in high temperature caustic solutions. Journal of Corrosion Science. 1997;39:1037-1049.

18. Bisbrown AJK. Fumigable warehouses: design and construction. Natural Resources Institute Bulletin No.53. Natural Resources Institute, Chatham, UK. 1992;28-38.

19. Australian Pork Limited, Pig housing and design in National environmental guidelines for piggeries, $2^{\text {nd }}$ Edition. Project number 2008/2231. 2010;40-45.

20. Sarwar G, Williams EA, Robinson AP. Survey of commercially available Wood and Agricultural Residue Combustion Systems. Engineering Series No. 1, Natural Resources Institute, Chatham, UK. 1992;21- 25.

21. Akelah A. Functionalized Polymeric Materials in Agriculture and the Food Industry. Springer Science \& Business Media. 2013.

22. Farm Machinery and Equipment Manufacturing. 1997 Economic Census, Manufacturing, Industry Series. U.S. Department of Commerce, Economics and Statistics Administration, U.S. Census Bureau, November; 1999.

(C) 2015 Oki and Anawe; This is an Open Access article distributed under the terms of the Creative Commons Attribution License (http://creativecommons.org/licenses/by/4.0), which permits unrestricted use, distribution, and reproduction in any medium, provided the original work is properly cited.

Peer-review history:

The peer review history for this paper can be accessed here: http://www.sciencedomain.org/review-history.php?iid=835\&id=33\&aid=7590 